DOI 10.37882/2500-3682.2020.12.31

\title{
ВНУТРЕННИЙ ДИАЛОГ ПРИ СОВЕРШЕНИИ ПОСТУПКА: УРОВНИ И ЭФФЕКТЫ
}

\section{INTERNAL DIALOGUE WHEN DOING A DEED: LEVELS AND EFFECTS}

\section{O. Pchelina}

Summary: The article reveals the theoretical idea of committing a deed through an internal dialogue that takes place on a conscious and unconscious level.

Empirical study has shown that when solving a complex life task, two types of internal dialogue contribute to increasing the level of maturity of a deed: explicit (conscious) and implicit (unconscious). The study sample con-sisted of 115 people aged 30-50 years. Methods of study are "Structured in-terview», «Internal Dialogical Activity Scale».

Keywords: deed, decision-making, internal dialogue, explicit dialogue, implicit dialogue.
$\mathrm{T}$ ема поступка, принятия важного решения в ситуации неопределенности никогда не утратит своей актуальности. Встречаясь с задачей на поступок, субъект стремится найти по возможности лучшее решение, придумать сравнительно новый способ разрешения конфликта, тем самым творить свое будущее и себя как личность. Многие исследователи, например, [18; 24; 26] природу личности и мышления видят во внутреннем диалоге.

Принятая в отечественной психологии аксиома социального происхождения сознания позволяет говорить о том, что принятие решения в трудной жизненной ситуации (взвешивание альтернатив, прогноз результата, поиск творческого решения и т.д.) есть интериоризированный процесс, который прежде был межсубъектным. Некогда развернутый вовне диалог вращивается внутрь, делая возможным диалог внутренний - «вид интраперсонального общения» [27, р. 2049], сомнения «опрос возможных позиций, каждая из которых обладает своим голосом и соответствующим набором аргументов в пользу отстаиваемой альтернативы» [5, с. 114]. Л.П. Гримак определяет внутренний диалог как «борьбу мотивов» - наличие различных точек зрения на собственные переживания и действия, «когда четко осознается потенциальное наличие различных способов действия» [4, с. 23-24], а разрешение мотивационного конфликта и есть поступок.

Проблема заключается в том, что, с одной стороны, поступок принято считать сознательным действием
Пчелина Ольга Викторовна

Аспирант, Тюменский государственный университет polga-mk@yandex.ru

Аннотация: В статье раскрывается теоретическое представление о совершении поступка посредством внутреннего диалога, протекаемого на осознаваемом и неосознаваемом уровне.

Эмпирическое исследование показало, что при решении сложной жизненной задачи повышению уровня зрелости поступка способствуют два вида внутреннего диалога: эксплицитный (осознаваемый) и импли-цитный (неосознаваемый). Выборка составила 115 человек 30-50 лет. Использованные методы исследования: «Структурированное интервью», «Шкала внутренней диалоговой активности».

Ключевые слова: поступок, принятие решений, внутренний диалог, эксплицитный диалог, имплицитный диалог.

[2, с. 326], [12, с. 26], а с другой - «бывает порой трудно назвать сознательным выбором то, чем мы руководствуемся» [13, с. 83], «одни знания и рассуждения, как правило, не являются достаточными для принятия благоприятного решения» [15, р. 337]. «Практически все, что раньше считалось исключительной прерогативой сознания: принятие сложных решений, семантические преобразования, постановка целей, социальные оценки, моральные суждения и многое другое, - все это вроде бы сначала делается неосознанно и лишь потом осознается» $[1$, с. 42].

Логично предположить, что помимо сознательного внутреннего диалога при совершении поступка есть еще иной вид внутреннего диалога, который, по аналогии с неосознаваемым мотивом по А.Н. Леонтьеву, «скрыт», и при этом «он действует, он побуждает» [9, с. 450].

Подтверждение идеи находим у нескольких авторов. Так, Ж. Лакан считает, что монолог в целом предполагает наличие другого, но и «бессознательное субъекта есть дискурс другого» [8, с. 35]. Л.В. Розанова выделяет осознанный и неосознанный внутренний диалог: между сознательными частями психического; между сознательными и бессознательными структурами психики; неосознаваемый диалог внутри бессознательного [10, с. 149]. Н.А. Евченко описывает внутренний диалог как «процесс внутренней коммуникации, актуализируемый проблемными ситуациями и протекающий в вербальной и невербальной формах» [6, с. 45]. 
Точка зрения, что большая часть эффективной обработки информации происходит вне осознавания, сегодня является все более разделяемой $[14 ; 19 ; 20]$. «Возможности бессознательной переработки информации зачастую превышают возможности сознательной когнитивной деятельности» [7, с. 136], а познавательные процессы протекают одновременно на двух уровнях: осознаваемом и неосознаваемом, и в их взаимодействии «имеют место как восходящие, так и нисходящие эффекты» [там же, с. 137] (эта идея будет использована в экспериментальном дизайне).

C. Эпштайн в рамках своей когнитивно-экспериентальной Я-теории (Cognitive-experiential self-theory) развивает представления о двух системах обработки информации. Рациональная (когнитивная) система - сознательная, относительно медленная, аналитическая, словесная; эмпирическая (экспериентальная) - быстрая, автоматическая, невербальная [25, р. 972]. При этом эмпирическая система «для решения проблем во многих обстоятельствах оказывается более эффективной, чем рациональная» [17, р. 719], поскольку ее компонентами являются, в частности, воображение и креативность [21].

Таким образом, есть достаточно теоретических оснований считать, что внутренний диалог при совершении поступка может протекать на двух уровнях: осознаваемом и неосознаваемом. Эксплицитный (осознаваемый) диалог сравнительно легко выносится вовне, в то время как имплицитный (неосознаваемый) практически не вербализуем. При этом имплицитный внутренний диалог может быть даже более эффективным при поиске творческого решения в задаче на поступок.

Под поступком понимается выбор между мотивационно оправданными поведенческими возможностями, за каждой из которых стоят альтернативные ценности. Уровень зрелости поступка определяется в соответствии с классификацией видов поступков Е.Л. Доценко:

1. Отказ от поступка - бездействие, игнорирование задачи на поступок.

2. Псевдопоступок - уступка обстоятельствам.

3. Ответственный поступок - выбор одной из альтернатив с отказом от второй.

4. Творческий (наиболее зрелый) поступок - решение, направленное на поддержание по возможности всех альтернатив и, соответственно, ценностей, составляющих суть ситуации $[5 ; 11]$.

Эмпирическое исследование направлено на подкрепление теоретического положения о роли двух уровней внутреннего диалога при совершении поступка.

Гипотезы:

1. Разворачивание эксплицитного внутреннего диалога способствует повышению зрелости поступ- ков.

2. Перевод диалога на имплицитный уровень способствует повышению зрелости поступков.

3. Между уровнем зрелости поступка и уровнем внутренней диалоговой активности наблюдается прямая положительная связь.

\section{Выборка}

В исследовании приняли участие 119 человек 30-50 лет, четыре протокола были отбракованы, таким образом рабочая выборка составила 115 человек ( $\mathrm{M}=37,957$, $\mathrm{SD}=5,810)$, из которых 61 жен., 54 муж.

\section{Метох}

Авторская методика «Структурированное интервью» (Е.Л. Доценко, В.А. Старцева, О.В. Пчелина) предназначена для выявления уровня зрелости поступков. Стимульный материал представляет собой пять проблемных ситуаций (задач на поступок). Процедура сбора данных состоит из четырех этапов:

1. Типичное принятие решения испытуемым в пяти проблемных ситуациях (начальные предпочтения).

2. Принятие решения в тех же ситуациях после беседы с воображаемым собеседником. Задача заключается в том, чтобы в диалоге с представляемой фигурой еще раз рассмотреть каждую задачу на поступок для поиска по возможности лучшего решения. Идея этапа процедуры - развернуть эксплицитный внутренний диалог.

3. Полезное отвлечение (придумывание названий для пяти абстрактных картинок). Предположительно, во время отвлечения на нерелевантную задачу внутренний диалог в отношении задач на поступок продолжился, но уже неосознаваемо. Идея этапа процедуры - актуализировать имплицитный внутренний диалог.

4. Окончательное, итоговое, принятия решений сразу после полезного отвлечения.

Для определения уровня поступка использовалась стандартизированная кодировка, в спорных случаях дискуссия для выработки единого мнения экспертовпсихологов. Уровень зрелости поступков оценивался по шкале от 0 до 8, где 0 - отказ от принятия решения и какого-либо действия (отказ от поступка); 8 - творческое решение, поддерживающее сразу две или более ценности (наиболее зрелый поступок).

Перед выполнением методики «Структурированное интервью» испытуемые заполняли опросник «Шкала внутренней диалоговой активности П. Олеся» (ШВДА) в адаптации Д.А. Астрецова и Д.А. Леонтьева (2015). Под внутренней диалоговой активностью П. Олесь понимает 
«вовлеченность в диалоги с воображаемыми фигурами, моделирование социальных диалогических отношений и взаимное противостояние точек зрения, представляющих различные Я-позиции, имеющих отношение к личной и / или социальной идентичности» [23 р. 242].

Опросник ШВДА включает три шкалы: «Внутренний диалог», «Внутренний мир» и «Внутренний конфликт». «Внутренний диалог» характеризуется как общий показатель диалоговой активности человека. «Внутренний мир» связан с мысленным моделированием окружающего мира, в основном в словесной форме. «Внутренний конфликт» отражает сферу внутренних противоречий, противостояний различных сторон личности человека [3].

Обработка данных выполнялась с помощью Microsoft Excel, SPSS Statistics20, STATISTICA10. Характер сдвига уровня зрелости поступков оценивался с помощью Т-критерия Вилкоксона (W).

\section{Результаты и обсужАение}

Таблица 1.

Значения уровня зрелости поступков

\begin{tabular}{|c|c|c|c|c|c|}
\multicolumn{2}{|c|}{$\begin{array}{c}\text { Второе решение после } \\
\text { Первое решение } \\
\text { разговора с вообража- } \\
\text { емым собеседником }\end{array}$} & $\begin{array}{c}\text { Окончательное реше- } \\
\text { ние после полезного } \\
\text { отвлечения }\end{array}$ \\
\hline $\begin{array}{c}\text { в пяти } \\
\text { задачах на } \\
\text { поступок }\end{array}$ & в среднем & $\begin{array}{c}\text { в пяти } \\
\text { задачах на } \\
\text { поступок }\end{array}$ & в среднем & $\begin{array}{c}\text { в пяти } \\
\text { задачах на } \\
\text { поступок }\end{array}$ & в среднем \\
\hline 18,252 & 3,650 & 19,426 & 3,885 & 20,339 & 4,068 \\
\hline
\end{tabular}

Визуализация результатов по изменению уровня зрелости поступков при проведении процедуры представлена на рис. 1.

Критерий Вилкоксона показал, что этап разговора с воображаемыми собеседниками (эксплицитный, вербализуемый диалог) статистически значимо повысил уровень зрелости поступков $T=617, Z=2,194, p=, 028$. Эксплицитный диалог, похоже, способствовал осознанному погружению в ценностный конфликт, уточнению условий и противоречий, лучшей ориентировке в сторону желаемого результата; поддерживал расширение зоны поиска, приращение, а не редукцию возможного репертуара действования.

Повышение уровня зрелости поступков после этапа полезного отвлечения так же является статистически значимым T $=761,5, Z=2,667, p=, 008$. Здесь мы склонны видеть работу имплицитного, неосознаваемого диалога. Исследования творческого процесса свидетельствуют, что мышление продуктивно на неосознаваемом уровне, который соотносится с фазами инкубации и вызревания инсайта $[28 ; 16]$. Возможно, имплицитный внутренний диалог более тотален в дискурсе внутренних позиций и поэтому обеспечивает принятие более творческого, зрелого, решения.

Совокупная работа двух уровней внутреннего диалога ожидаемо повысила уровень зрелости поступков $\mathrm{T}=643, \mathrm{Z}=4,359, \mathrm{p}=, 000$.

Таким образом, гипотезы 1 и 2 получили подкрепление.

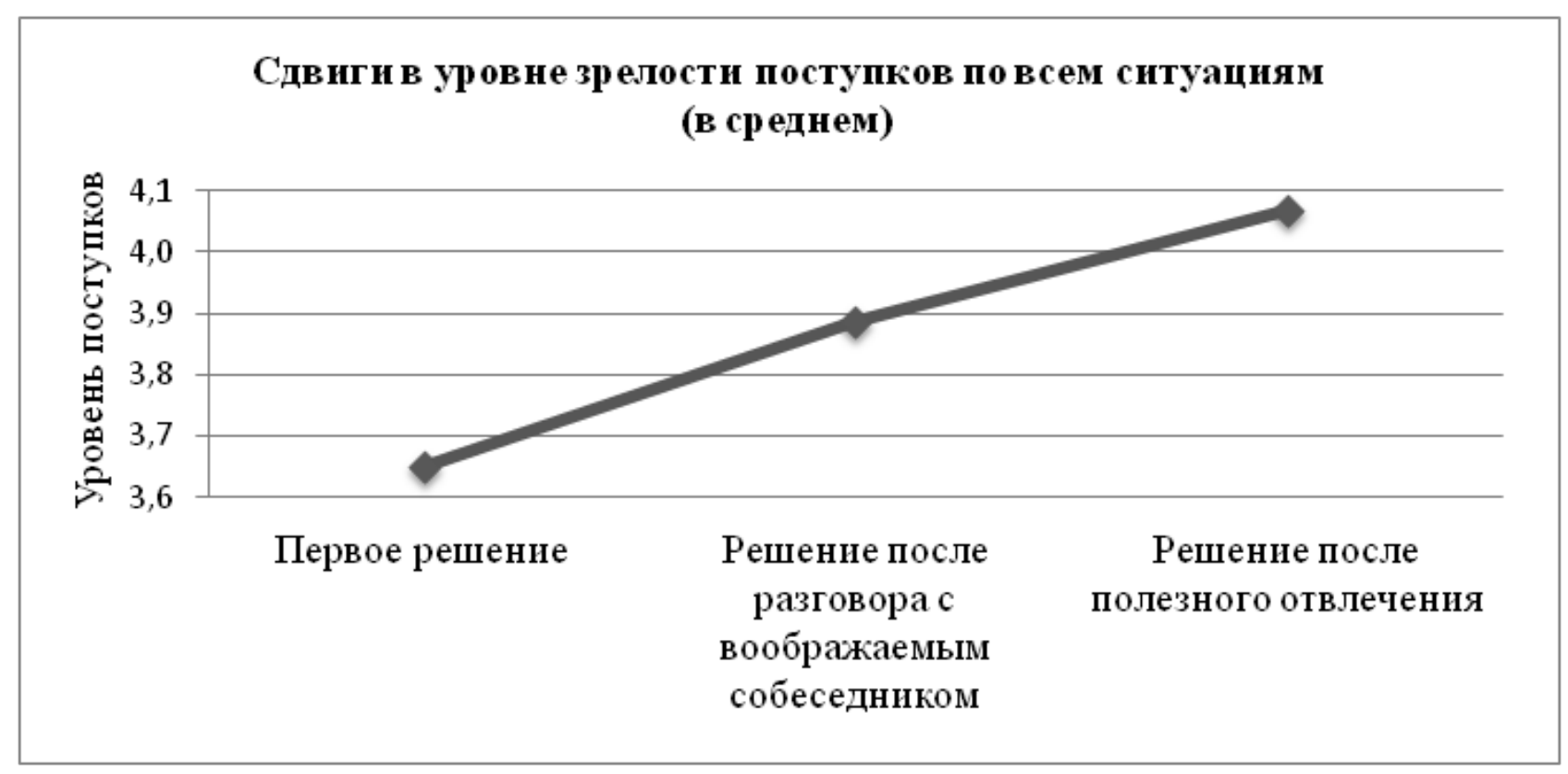

Рис. 1. Сдвиги в уровне поступка (в среднем) 
Таблица 2.

Результаты корреляционного анализа уровней зрелости поступков со шкалами опросника ШВДА

\begin{tabular}{|l|c|c|c|c|}
\hline & ШВДА & $\begin{array}{c}\text { Внутренний } \\
\text { Диалог }\end{array}$ & $\begin{array}{c}\text { Внутренний } \\
\text { Мир }\end{array}$ & $\begin{array}{c}\text { Внутренний } \\
\text { Конфликт }\end{array}$ \\
\hline $\begin{array}{l}\text { Первое решение } \\
\text { Второе решение после } \\
\text { разговора с вообража- } \\
\text { емым собеседником }\end{array}$ & $-0,126$ & $-0,071$ & $-0,009$ & $-0,264^{*}$ \\
\hline $\begin{array}{l}\text { Окончательное реше- } \\
\text { ние после полезного } \\
\text { отвлечения }\end{array}$ & $-0,095$ & $-0,037$ & $-0,029$ & $-0,174$ \\
\hline
\end{tabular}

Примечание. Представлены коэффициенты корреляции r-Спирмена (Spearman Rank Order Correlations). * - корреляция значима на уровне $p<, 05$

Неожиданным оказался слабый результат корреляции уровня поступка с факторами опросника «Шкала внутренней диалоговой активности» Как видно из таблицы 2, на уровне статистической значимости только связь шкалы «Внутренний конфликт» с первым (типичным для испытуемого) и с окончательным решениями. Причем все полученные величины (как значимые, так и не значимые) корреляционного анализа имеют отрицательный знак! Эти данные, казалось бы, не только не подкрепляют гипотезу 3, но и противоречат рассмотренной нами теории.

Однако, во-первых, ШВДА выявляет скорее представления испытуемых о собственном уровне диалоговой активности, чем фактическую сложность внутреннего диалога. Тем более, что часть внутреннего диалога (его имплицитный уровень) остается за границами осознавания, а значит, не может быть замерен прямыми вопросами. Как резонно замечает П. Олесь, не все внутриличностные коммуникации представлены в сознании, опросники ограничиваются лишь теми ситуациями и переживаниями, которые респонденты могут вспомнить [22].

И, во-вторых, Д.А. Астрецов и Д.А. Леонтьев обращают внимание на некоторую ограниченность инструментария ШВДА, поскольку факторы опросника «отражают скорее негативный и деструктивный полюс внутреннего плана личности» [3, с. 79].

Внутренняя диалоговая активность, согласно ав- тору опросника П.Олесю, заостряет интеграцию или конфронтацию различных точек зрения [22]. PuchalskaWasyl описывает интегративные и конфронтационные внутренние диалоги следующим образом: первые направлены на учет и интеграцию всех вовлеченных точек зрения и, следовательно, могут привести к творческим решениям. Конфронтационные внутренние диалоги, напротив, подчеркивают различия между точками зрения и стремятся усилить одну из них, игнорируя или осуждая другие [26, с. 249].

Поскольку испытуемые по ходу процедуры обследования повышали уровень зрелости поступков (в том числе с точки зрения поиска творческого решения), а положительной корреляции со шкалами ШВДА нет, можно предположить, что при работе с ситуациями, содержащими задачу на поступок, испытуемые актуализировали интегративный внутренний диалог, а заполняя опросник ШВДА - конфронтационный. Как замечают Д.А. Астрецов и Д.А. Леонтьев, «ответы по всем шкалам демонстрируют значимую связь с такими неблагоприятными характеристиками, как низкое самоотношение, склонность к самообвинению, ощущение неблагополучия жизни» [3, с. 79].

\section{Выво $\Delta ы$}

Проведенное исследование позволяет сделать вывод о подкреплении теоретических представлений о решении задачи на поступок посредством внутреннего диалога, протекающего на двух уровнях: эксплицитном (осознаваемом) и имплицитном (неосознаваемом). Показано наличие эффектов от двух уровней внутреннего диалога: повышению зрелости поступка способствуют как эксплицитный, так и имплицитный. Похоже, что методика «Структурированное интервью» способствует интеграции различных внутриличностных позиций, содействуя поиску творческого решения в задаче на поступок.

Полученная значимая отрицательная связь первого, типичного для испытуемого, и окончательного решений со шкалой «Внутренний конфликт» опросника ШВДА (все прочие связи незначимы и отрицательны), возможно, говорит о том, что с помощью методики «Шкала внутренней диалоговой активности» выявлена выраженность конфронтационных внутренних диалогов. Однако это предположение требует нашей дальнейшей исследовательской работы.

\section{ЛИТЕРАТУРА}

1. Аллахвердов В.М. Сознание, научение и контроль: вперед к теории // Вестн. С.-Петерб. ун-та, Сер. 16. Психология. Педагогика. 2014. Вып. 4. С. 41-51.

2. Анцупов А.Я., Шипилов А.И. Словарь конфликтолога / А.Я. Анцупов, А.И. Шипилов. 2-е изд. — Спб.: Питер, 2006. — 528 с.: ил.

3. Астрецов Д.А.; Леонтьев Д.А. Психодиагностические возможности «Шкалы внутренней диалоговой активности» П. Олеся // Вестник Московского университета. Серия 14: Психология. 2015. № 4. С. 66-82.

4. Гримак Л.П. Общение с собой: начала психологии активности. Изд. 3-е. М.: Книжный дом «ЛИБРОКОМ», 2009. 336 с.

5. Доценко Е.Л. Психология личности: Учебное пособие. Тюмень: ТюмГУ, 2009. С. 512. 
6. Евченко Н.А. Внутренняя коммуникация «Я - Другое Я» в динамике субъектных проявлений личности: дисс. ... к-та псих. наук. Москва, 2015. 186 с.

7. Куделькина Н.С., Свиридова Т.А. Семантический перенос как эффект взаимодействия осознаваемого и неосознаваемого уровней познания // По обе стороны сознания. Экспериментальные исследования по когнитивной психологии. Самара: Издательский Дом «Бахрах-М». 2012. С. 135-151.

8. Лакан Ж. Функция и поле речи и языка в психоанализе. М.: Гнозис. 1995. С. 192.

9. Леонтьев А.Н. Лекции по общей психологии. М.: Смысл, 2000. С. 511.

10. Розанова Л.В. Внутренний диалог как фактор преодоления жизненного кризиса. Омский научный вестник. 2008. №3 (67). С. 148-150.

11. Старцева В.А. Роль поступков в достижении личностной интегрированности: дисс. ... к-та псих. наук. Екатеринбург, 2016. 205 c. Режим доступа: httр://lib. urfu.ru/mod/data/view.php?d=51\&rid=259805\&filter=1

12. Тульчинский Г.Л. Разум, воля, успех. 0 философии поступка / Г.Л. Тульчинский. Л.: Издательство Ленинградского Университета. 1990. С. 216.

13. Хахалова А.А. Судьба влечений в этике психоанализа // Вестник ЛГУ им. А.С. Пушкина. 2010. №3. С. 79-86.

14. Aldous C.R. Attending to Feeling: It May Matter More than You Think // Creative Education. 2014. Vol. 5. № 10. DOl: 10.4236/ce.2014.510091

15. Bechara A., Damasio A.R. The somatic marker hypothesis: A neural theory of economic decision // Games and Economic Behavior. 2005. Vol. 52, № 2. P. 336-372.

16. Botella M., Zenasni F., Lubart T. What Are the Stages of the Creative Pro-cess? What Visual Art Students Are Saying // Frontiers in Psychology. 2018. Vol. 9. https:// doi.org/10.3389/fpsyg.2018.02266

17. Epstein S. Integration of the Cognitive and the Psychodynamic Unconscious // American Psychologist. 1994. Vol. 49. № 8. P. 709-724 D0I: 10.1037//0003066X.49.8.709

18. Hermans H.J. The Dialogical Self: Toward a Theory of Personal and Cultural Positioning // Culture \& Psychology. 2001. Vol. 7. № 3. P. $243-281$.

19. Kiefer M. Cognitive control over unconscious cognition: flexibility and gen-eralizability of task set influences on subsequent masked semantic priming // Psychological Research. 2019. № 83. P. 1556-1570 https://doi.org/10.1007/s00426-018-1011-x

20. Michael I., Ramsoy T., Stephens M., Kotsi F. A study of unconscious emo-tional and cognitive responses to tourism images using a neuroscience method // Journal of Islamic Marketing. 2019. Vol. 10. № 2. P. 543-564. https://doi.org/10.1108/JIMA-09-2017-0098

21. Norris P., Epstein S. An experiential thinking style: Its facets and relations with objective and subjective criterion measures // Journal of Personality. 2011. Vol. 79. № 5. P. 1043-1079. https://doi.org/10.1111/j.1467-6494.2011.00718.x

22. Oles' P.K., Brinthaupt T.M., Dier R. and Polak D. Types of Inner Dialogues and Functions of Self-Talk: Comparisons and Implications // Frontiers in Psychology. 2020. Vol. 11. https://doi.org/10.3389/fpsyg.2020.00227

23. Oles' P.K., Puchalska-Wasyl M. Dialogicality and personality traits // In H. Hermans \& T. Gieser (Eds.), Handbook of Dialogical Self Theory. Cam-bridge: Cambridge University Press. 2012. P. 241-252. https://doi.org/10.1017/CB09781139030434.017

24. Osatuke K., Gray M., Glick M., Stiles W., Barkham M. Hearing voices: Methodological issues in measuring internal multiplicity // In H. Hermans, \& G. Dimaggio (Eds.), The dialogical self in psychotherapy. Brunner-Routledge. 2004. P. 237-254. D01: 10.4324/9780203314616

25. Pacini R., Epstein S. The relation of rational and experiential information processing styles to personality, basic beliefs, and the ratio-bias phenomenon // Journal of Personality and Social Psychology. 1999. Vol. 76. № 6. P. 972-987. https://doi.org/10.1037/0022-3514.76.6.972

26. Puchalska-Wasyl M.M. Determinants of Integration and Confrontation in Internal Dialogues // Japanese Psychological Research. 2016. Vol. 58. № 3. P. 248-260. doi:10.1111/jpr.12115

27. Puchalska-Wasyl M.M., Zarzycka B. Internal Dialogue as a Mediator of the Relationship Between Prayer and Well-Being // Journal of Religion and Healt. 2020.59. P. 2045-2063. https://doi.org/10.1007/s10943-019-00943-2

28. Zhong C., Dijksterhuis A., Galinsky A.D. The merits of unconscious thought in creativity // Psychological science. 2008. Vol. 19. № 9. P. 912-918. https://doi. org/10.1111/j.1467-9280.2008.02176.x

(c) Пчелина Ольга Викторовна (polga-mk@yandex.ru).

Журнал «Современная наука: актуальные проблемы теории и практики» 